\title{
EL PSICOANALISTA RELACIONAL Y SUS APEGOS
}

\author{
José Ángel Aguilar, Adriana Dávila, Amalia Rivera, Lucía Chávez, \\ Norma Vidaurri, Karla Rodríguez y Roberto Vargas \\ Asociación Mexicana de Psicoterapia y Psicoanálisis Relacional (AMPPR)
}

\begin{abstract}
Este trabajo tiene el propósito de elucidar sobre el psicoanalista relacional y sus apegos, a partir de cuatro preguntas eje que un grupo de psicoanalistas relacionales mexicanos que conformamos la Asociación Mexicana de Psicoterapia y Psicoanálisis Relacional (AMPPR) y el capítulo México Contemporáneo de la IARPP respondimos en función de nuestra práctica clínica y nuestra subjetividad. Las preguntas fueron ¿Por qué es importante la teoría del apego para el psicoanálisis relacional? ¿Qué apegos identificamos en nuestros pacientes? ¿Qué apegos identificamos en nuestra práctica clínica y en nuestra persona? Y ¿Cómo entran en juego estos apegos en la habitación de lo íntimo, haciendo referencia al espacio analítico?. Para los autores la teoría del apego es importante para el psicoanálisis relacional por la relevancia del vínculo con las figuras de apego, que encuentran caminos complejos en momentos históricos específicos, además de comprender los patrones relacionales del paciente y el tipo de interacción que podemos esperar a lo largo del proceso psicoterapéutico. Las y los autores hablamos sobre experiencias personales de los diferentes tipos de apego que vivimos con nuestros pacientes en el espacio clínico, a través de viñetas breves.
\end{abstract}

Palabras clave: apego, psicoanálisis relacional, subjetividad, práctica clínica, persona

The purpose of this work is to elucidate the relational psychoanalyst and its attachments, based on four main questions responded by a group of Mexican relational psychoanalysts who comprise the Mexican Association of Relational Psychotherapy and Psychoanalysis (MARPP) and Mexico Contemporary chapter of the IARPP according to our clinical practice and our subjectivity. The questions were: Why is attachment theory important for relational psychoanalysis? What attachments do we identify in our patients? What attachments do we identify in our clinical practice and in our person? And, how do these attachments come into play in the intimate room, referring to the analytical space? For the authors, attachment theory is important for relational psychoanalysis because of the relevance of the link with attachment figures, which find complex paths at specific historical moments, in addition to understanding the patient's relational patterns and the type of interaction we can expect throughout the psychotherapeutic process. The authors talk about personal experiences of the different types of attachment lived with our patients in the clinical space, through brief points.

Key Words: attachment, relational psychoanalysis, subjectivity, clinical practice, person. English Title: RELATIONAL PSYCHOANALYST AND ITS ATTACHMENTS

\section{Cita bibliográfica / Reference citation:}

Aguilar, J.A., Dávila, A., Rivera, A., Chávez, L., Vidaurri, N., Rodríguez, K. y Vargas, R. (2020). El psicoanalista relacional y sus apegos. Clínica e Investigación Relacional, 14 (1): 69-76. [ISSN 19882939] [Recuperado de www.ceir.info] DOI: 10.21110/19882939.2020.140104 
El psicoanálisis relacional trata de integrar aquellas teorías que abordan la relación intersubjetiva como el elemento más importante para el desarrollo del psiquismo. Así la teoría del apego es considerada como una conducta primaria y diferenciada de la necesidad alimentaria y sexual, esto significa la tendencia de los seres humanos a crear lazos afectivos con personas significativas, con la idea de comprender la influencia del apego en la personalidad y las emociones humanas. Esta teoría reconoce que el modelo relacional entre los niños, las niñas y sus padres, madres o cuidadores se convierte en estructura interna, o sea, en un sistema representacional, con una base segura.

El apego se constituye de múltiples sensaciones agradables, desagradables, violentas, suaves, cargadas de elementos no dichos que quizá se puedan o no traducir en palabras. Estas primeras experiencias encaminadas por las sensaciones mediante la evolución de los sentidos establecen los puentes de los inconscientes implícitos que están y estarán enmarcados por las relaciones vinculares estableciendo un tipo de apego, que estarán describiendo, inscribiendo o no los acercamientos con quienes ejercen las funciones materna y paterna.

Bowlby, al plantear los modelos operativos internos señala que podemos tener apegos con figuras cercanas de forma diferente. Así, se puede tener apego con ambos padres, con un padre o una la madre, inclusive con la abuela $u$ otro cuidador, también nos dice que un niño puede tener diferentes modelos operativos, en diferentes momentos relacionales con sus padres.

Tener un apego seguro marcará de alguna manera varias áreas del ser humano, desde la capacidad para mentalizar, para sostenerse en la vida, para relacionarse. El apego es la primera puerta del mundo relacional, en donde se construye un vínculo, es decir, un tercero en ese espacio, conformando las capacidades más elaboradas del ser humano como la posibilidad de reconocer al otro en su subjetividad. En suma, la teoría del apego es importante para el psicoanálisis relacional por la relevancia del vínculo con las figuras de apego, que encuentran caminos complejos en momentos históricos específicos, además de comprender los patrones relacionales del paciente y el tipo de interacción que podemos esperar a lo largo del proceso psicoterapéutico.

En la historia relacional de nuestros pacientes hemos identificado que prevalecen patrones de apego inseguro ambivalente, ansioso y desorganizado, con dudas entre acercarse y alejarse de las figuras de apego, con dificultades en la regulación emocional. Provienen de relaciones con los padres o los cuidadores primarios que se caracterizaron por una escasa disposición afectiva, con ausencias prolongadas o por un sobreinvolucramiento que se vivió 
a modo de intrusión. En ambos casos, deja un sentimiento de inseguridad, de falta de sostén y contención.

Los apegos que cada paciente presenta están en condición de ser analizados desde su singularidad en una pluralidad contextual, de desarrollo de vida en diferentes ámbitos: laboral, familiar, en la relación de pareja, así como en el ciclo vital. Es importante observar que cada paciente viene con una historia e interpretación de la vida en cada contexto, exponiendo sus miedos, angustias, ambivalencia, inseguridades ante sí mismo y ante las funciones en donde desempeña alguna expresión vincular de sus roles y funciones.

Desde otro ángulo, los apegos que identificamos en nuestra práctica clínica y en nuestra persona aluden a apegos seguros e inseguros. La interacción con nuestras figuras de apego nos dejó ambas experiencias transitorias. Al respecto, identificamos sensibilidad ante el rechazo, temores de abandono, necesidades de abandonar antes de ser abandonado, temores de no ser suficiente, necesidad de apego a las personas, inseguridad, miedo, intranquilidad y angustia frente a aquellos elementos que toman más tiempo de pensar $y$ reflexionar, y que en ocasiones se presentan hasta en los sueños.

En este aspecto las y los autores hablamos sobre experiencias personales de los diferentes tipos de apego que vivimos con nuestros pacientes en el espacio clínico, a través de viñetas clínicas breves. Lupita, por ejemplo, tiene 75 años, su motivo de consulta es que se separó de su marido y ha estado en duelo por dos años, relata que fue maltratada por él de varias formas: En el aspecto emocional utilizaba sus conocimientos de Psiquiatría para afectarla de un modo sádico, se acostaba con sus pacientes y también tuvo de amante a su asistente por varios años en su consultorio que estaba en su propia casa. Se trabajó aproximadamente cuatro años con la paciente, con el fin de que tuviera autonomía, lograra vencer el miedo que le daba enfrentar a su ex marido, y que pudiera hacer un plan de vida más allá de ser esposa y madre.

La paciente mantuvo un apego ambivalente que no le permitía dejar de pensar y actuar respecto de su exmarido, logramos descubrir que era un patrón relacional parecido al vínculo con su madre, se logró un apego adecuado al tratamiento, siendo una paciente puntual, disciplinada y analítica. Nuestra relación fue fuerte y con un patrón relacional madre-hijo. Logramos un apego seguro, que nos permitió buscar su autonomía al desapegarse de su ex marido, y diseñar su propio plan de vida: hacer ejercicio, salir sola o con una amiga, cambiarse de casa y enfrentar a su entonces pareja. Sin embargo, su hija se embarazó y a la llegada de su nieto, ella espació sus sesiones. José Ángel Aguilar, su analista, refiere que esta situación la resintió y "aunque lo trabajamos, la fuerza del amor a su nieto y la necesidad de apoyar a su hija, soltera, la llevó a abandonar, previo aviso de hacer una pausa, el tratamiento". 
José Ángel Aguilar refiere: "Considero que hicimos un trabajo adecuado al cambiar el apego al ex marido, después conmigo, y ahora con su nieto. Me quedó la impresión que yo también tuve una relación de apego que ayudó pero me dejó triste su partida, ya que descubrí mi necesidad de apego con una madre, que yo necesitaba, ella estaba pendiente de mi salud y se preocupaba por algunas cosas, como mis plantas, sin hacer preguntas directas lo hacía de manera no verbal o con actitudes de aprecio y empatía. El apego se dio de ambas partes durante el proceso, pero se convirtió en un apego adecuado, que logró su autonomía, aunque a mí me haya dejado nostálgico (porque volvía vivir apego materno) con ganas de que el tratamiento continuara, por la relación intersubjetiva nos hizo crecer a ambos".

Emmanuel, por otro lado, es un joven de 30 años, originario de un Estado al sur de la República Mexicana, que acude a terapia por un proceso de rompimiento de relación después de estar casado por un año y de vivir con ella otros tres más. Sus planes se vinieron abajo con la noticia de una intención de divorcio por parte de su entonces esposa, quien en un inicio mostró dudas sobre qué hacer. Emmanuel sintió una incertidumbre insoportable que lo llevó a presionarla para que tomara una decisión. La razón del divorcio es que estaba inconforme con la actitud de Emmanuel, quien a veces se mostraba controlador, celoso, insatisfecho y violento.

Ante la amenaza de rompimiento, Emmanuel fue hiriente e incisivo con ella, pero en el trasfondo de su actitud se asomaba un dolor intenso asociado con pérdida y con falta de control. Él mismo se preguntaba por qué sentía tanto dolor y se comparaba con sus amigos, quienes aparentemente no sufrían tanto en situaciones similares. La posible respuesta a su interrogante es la siguiente: Emmanuel perdió a su padre, pero en condiciones poco usuales. Estuvo en la cárcel los primeros años de su vida por actividades ilícitas asociadas a la droga, salió y convivió con él un año para después morir por un accidente aéreo que se presume no fue un "accidente".

La pérdida de su padre lo deja en un espacio suspendido, no es de aquí ni de allá, no echa raíces en ningún lado y siempre se asoma la idea de que otros no padecen lo que él. Culpa a su madre, por no haberlo hecho firme y seguro y se lamenta de no tener claro su futuro, ni tener energía o motivación para hacer algo con él. Su principal objetivo es tener dinero pero no sabe para qué y le duele no poder compartirlo con alguien. Su madre, aquejada de depresión y su hermana de un cuadro paranoide, lo dejan con un sentimiento de vacío y de sinsentido y se aferra a su ex esposa, aunque después la olvida e intenta sostenerse de él mismo con infructuosos resultados.

Roberto Vargas, su analista, puntualiza que lo que puede salvar a Emmanuel es la relación terapéutica y los sentimientos que se cruzan que, desde su sentir, son fuertes y poderosos. 
Refiere: "En particular, el espacio de Emmanuel está destinado a tolerar la soledad y acompañarse, pero a partir de que yo también me siento fuertemente implicado con su dolor, con su pérdida y con su actitud titubeante. El sentimiento lo lleva a que ese espacio sea distinto a otras relaciones donde predomina el apego evitativo, es un ensayo de acercamiento hacia el afecto donde las palabras también acompañan y dan un poco de luz. Al final desconozco a qué puerto se llegará, lo que sé es que el proceso de terapia va marcando una ruta hacia la relación, hacia que él pueda implicarse afectivamente con su historia y no la ignore, no la odie, ni se lamente por ella. Sus sentimientos de pérdida me han llevado a sentir de manera intensa y profunda mis propios sentimientos de pérdida y el manejo que hice de ellos. En mi caso perdía mi madre y muchos años viví muy enojado y lamentado por la situación, asociando que el sufrimiento que derivaba de este suceso, era la razón de todos los pesares de mi existencia. Lo que me salvó fueron mis vínculos actuales que me mostraron que pesaban más las presencias que una ausencia fundamental, me sentí muy liberado de rodearme de personas vivas y no de una que había muerto, aspecto que se juega importantemente en el vínculo que tengo con Emmanuel y por lo que me siento implicado afectivamente con su existencia, más allá de ser un paciente, visualizo nuestro encuentro como un espacio en el que pausamos la muerte y nos devolvemos la vida".

Por otro lado, Norma Elena Vidaurri, nos dice: "Hace algunos meses empecé a sentirme muy agotada de la queja y del mundo sombrío y oscuro que mi paciente ha padecido por la separación de su pareja y que en las últimas semanas se incrementó por encuentros esporádicos en el terreno sexual, sin continuación cotidiana de charla, salidas, un trato amable hacia ella o una posible reconciliación. Ella planteó que ya era hora de dejar el análisis porque no había tenido éxito en su relación de pareja. Sesiones posteriores llegaba hablando de lo que le sucedía dejando de lado la petición de dejar el análisis, lo retomaba yo y ella expresaba "sí, para la próxima".

Leticia es una mujer de 60 años, tiene 5 años en análisis una vez a la semana con grandes dificultades en el pago de las sesiones, siendo una paciente becada. El motivo de consulta es la ruptura de una relación de 4 años con su primo hermano, única relación amorosa que ha tenido. Es la tercera hija de cuatro, el menor es hombre, su madre con esquizofrenia y el padre muy cauto y desconfiado del mundo exterior. Licenciada en Psicología que no ejerció; estudió inglés y ha trabajado en diversas e instituciones, actualmente en una escuela pública.

Con pocas amistades, en su trabajo la convivencia laboral es muy restringida, refiere "no caer bien" por su carácter intolerante y de expresión agresiva. La relación con su hermana y hermano también es muy austera. La hermana mayor muere de cáncer y padecía de esquizofrenia, Leticia era muy cercana a ella, su muerte cuando tenía 18 años le afectó y se 
sintió aún más restringida y con mucha desconfianza a estar fuera de su hogar. Sale poco, tiene pocas amistades y casi nada de convivencia social; solo sale para ir a la escuela a estudiar.

La muerte de la madre y del padre le deja como herencia un departamento que es el que habita, acompañada de algunos muebles de su casa materna y paterna. Pasaron tres años de análisis y ella empezó a participar en grupos de baile, cursos en la cineteca, salidas en grupo de vacaciones y a relacionarse con algunos hombres que ella ve como posibilidad para una relación amorosa, sin éxito.

Frente a estas experiencias en carne viva, frente a frente, grupales y de paseos y ante lo "no posible", se conecta con las redes sociales, en donde se encuentra con un hombre unos años mayor que ella. Su relación con él inicia intensamente, ella experimenta por primera vez la relación sexual genital ya que lo que ella y su primo hermano tenían era una relación sexual oral acompañado de fumar marihuana. Esta nueva experiencia sexual le abre el mundo íntimo de querer estar acompañada, no solo en la danza íntima de su hogar, sino en el ansia de convivir de la mano con él y conocer el mundo. Después de haberse separado hace un año en el último mes se comunicaron, tuvieron sexo y nada más, "los activos para soportar la realidad" se derrumban.

Norma Elena Vidaurri retoma: "La sesión inmediata a la supervisión relacional donde mis sensaciones están más acotadas por mi calma y seguridad de contener y sostener a Leticia sin el cansancio sentido con anterioridad, hacen la escucha más continente y lo suficientemente segura donde emerge el respiro nutriente de la seguridad de lo que Leticia ha realizado en nuestro vínculo y yo en esta relación. Así los "activos de movimiento para soportar la realidad" se reactivan, y nos sostienen en esta relación analítica; podemos hablar del desarrollo emocional y de sociabilidad que ella ha tenido, del dolor de la rupturas de las frustraciones de no escuchar en el análisis lo que hay que hacer y sobre todo la validación de ejecutar su decisión de cerrar o no el análisis".

Retoma: "Reconocer mi apego lo suficientemente seguro permite sostener mi capacidad, mi fragilidad, lo que me es posible y lo que no; reconocer y validar las capacidades y experiencias de mis pacientes llevan a buen puerto mi trabajo como psicoanalista y en mi humanidad como mujer y persona. Lo complejo, lo que es difícil, expone a pensar más allá de lo que marcha bien, como esa sutil experiencia vital de ser sostenido y sostener, de saber detectar que lo que sostiene a tus pacientes también te sostiene, no eres sin el otro y el otro no es sin uno, evolucionar implica desprenderse lo suficiente para existir".

Finalmente, María de 58 años, solicita consulta por haber sido agredida por su ex-pareja introduciendo una jeringa en el pecho con xilocaína, la cual afectó un pulmón, esto como 
consecuencia de dar por terminada la relación por parte de ella. El día de la agresión él la trasporta a un Hospital y la abandona en urgencias.

Su relación de varios años estuvo basada en una evidente violencia, sobre todo psicológica, aunque también económica y física. En un inicio se trabajó dando contención y sobre todo brindándole lo necesario para restablecer su seguridad. Posteriormente se trabajó en su relación que se caracterizaba por un apego ambivalente, dudaba si estaba haciendo lo correcto y por momentos justificaba la actuación de su ex -pareja por amor.

Al avanzar en su proceso, expresó que este mismo apego era semejante al vínculo con su padre que se caracterizaba por ser controlador, colmado de descalificaciones y maltrato hacia ella, donde no se le permitía que alcanzara sus sueños, por ejemplo ser una nadadora de alto rendimiento cuando ella destacaba en este deporte, lo cual fue rotundamente negado por el padre.

Ella elige como profesión la medicina para intentar ser aceptada y reconocida por su padre, ya que también era médico aparentemente exitoso, situación que no logró, al contrario: su padre se alejó más de ella y no fue apoyada dentro de esta labor. Estaba enojada con su madre por no haber intervenido para defenderla, posición que después quedó clara ya que vivía sumamente deprimida por el patrón relacional de violencia que imperaba en el hogary que en algún momento su madre intentó divorciarse y salir de su casa, situación que no logró. Lucía Chávez, su analista, nos dice: "Se obtuvo con ella un avance importante, consigue demandar a la ex -pareja que con anterioridad se negaba a hacerlo por miedo a volver ser agredida o tener que confrontarlo, el no recuperar sus pertenencias que se quedaron en el hogar, iniciar desde prácticamente en cero para retomar su vida, aceptarse, validarse, quererse y ser merecedora por todo lo que es ella y no desde la visión de los demás. La conexión con María fue desde un inicio empática para entender su dolor y tratar de generar un apego seguro para reconstruir el apego ambivalente generado en su infancia y con las consecuencias que esto implicaron en su vida".

En suma, con las viñetas clínicas presentadas y el tejido de las preguntas que nos dieron eje, consideramos que lo fundamental en nuestros procesos formativos como psicoanalistas relacionales es estar dispuestos al encuentro intersubjetivo y al cambio ya que implica la posibilidad de re-editar los patrones habituales y encontrar también una base segura. El encuentro entre estos patrones de apego pauta la posibilidad de acercarse afectivamente a los sentimientos de inseguridad, dolor, temor, ansiedad, rechazo, dependencia, aprehensión, confianza, amor, protección, constancia y apego adecuado, que 
experimentamos pacientes y terapeutas, en los vínculos intersubjetivos, dentro del espacio terapéutico.

\section{REFERENCIAS}

Bowlby, J. (1980). El apego. Buenos aires: Paidós

Marrone, M. (2001). La teoría del apego: un enfoque actual. Madrid: Psimática

Marrone, M. y Cortina, M. (2017). Apego y psicoterapia: Un paradigma revolucionario. Madrid:

Psimática

Original recibido con fecha: 1/12/20129 Revisado: 30/12/2019 Aceptado: 15/03/2020

NOTAS: Las notas han de ir indexadas en el texto como notas al final 